\title{
Woman in grey: hydroxychloroquine-induced hyperpigmentation
}

\author{
Rita Ivo, ${ }^{1}$ Carina Alves Lopes, ${ }^{2}$ Rita Reis ${ }^{1}$
}

'Internal Medicine, Hospital de Egas Moniz, Lisboa, Portugal ${ }^{2}$ Rheumatology, Hospital de Egas Moniz, Lisboa, Portugal

\section{Correspondence to}

Dr Rita Ivo,

rita.d.ivo@gmail.com

Accepted 28 October 2018

\section{DESCRIPTION}

The authors illustrate the case of a woman in her $80 \mathrm{~s}$ with history of systemic lupus erythematosus and Sjögren syndrome. She had lost medical follow-up with her rheumatologist in the last 3 years due to progressive functional and cognitive impairment but she was still taking prednisolone $5 \mathrm{mg}$ per day and hydroxychloroquine $400 \mathrm{mg}$ per day for, at least, the past 11 years. She was admitted in the internal medicine ward for an acute medical condition unrelated to the present report. The physical examination was remarkable for skin changes: brown to grey or black reticulated macules on the face and confluent patches on the anterior side of legs and forearms (figure $1 \mathrm{~A}-\mathrm{C}$ ), mainly in areas of previous bruising; there was no involvement of the mucous membranes or nail bed. The previous ophthalmological examination had been made 3 years before and there was no sign of retinal involvement. A skin biopsy was performed and showed pigment deposition in superficial dermis with haemosiderin characteristics-Perls Prussian staining was positive for iron and Fontana-Masson staining was negative for melanin. This skin hyperpigmentation was identified as an hydroxychloroquine adverse effect based on ongoing exposure and the drug was suspended; unfortunately it was not possible to see an improvement due to early death of the patient.

The long-term use of hydroxychloroquine in systemic lupus erythematosus treatment is associated with skin lesions in about 7\%-29\% of the patients. ${ }^{12}$ It usually involves the oral mucosa, shins, nails, forearms and anterior side of the legs. ${ }^{12}$ The time of onset ranges from few months to years after starting treatment, opposite to the ophthalmological adverse effects that

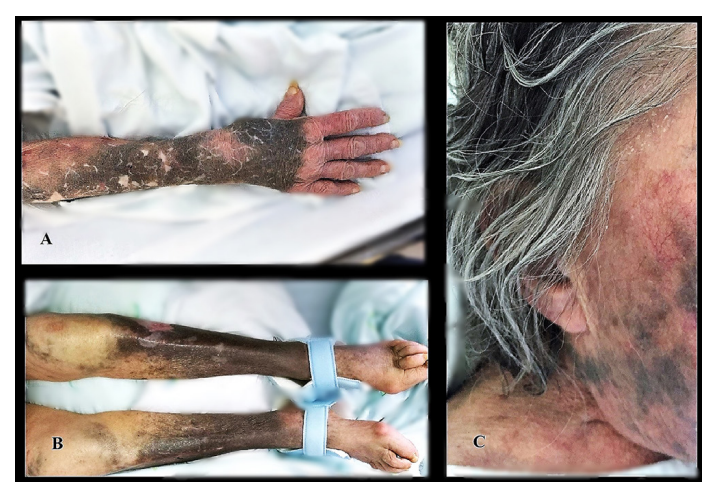

Figure 1 Hyperpigmented skin lesions in the anterior side of the legs and arms (A); legs (B) and face (C). are associated with duration and cumulative dose of hydroxychloroquine. Although the mechanism for hyperpigmentation is still poorly understood, there are some risk factors to consider, most of them related to easy bruising conditions, such as: use of anticoagulants or antiplatelet agents, prolonged use of corticosteroids, skin trauma or antiphospholipid syndrome. ${ }^{1-3}$ The skin biopsy usually shows melanin granules and haemosiderin deposits with an elevated iron skin concentration, leading to believe that this discolouration usually occurs in areas of previous bruising. ${ }^{12}$

The only treatment for this skin hyperpigmentation is discontinuing hydroxychloroquine, but it can take several months to improve the skin changes. Complete clearance is rare. ${ }^{2}$

\section{Learning points}

- Although hydroxychloroquine toxicity is more known as affecting the eyes, it is also associated with skin hyperpigmentation regardless of the duration of the treatment.

- The main risk factors are conditions that lead to easy bruising; the skin biopsy usually shows deposits of iron and melanin found in previous ecchymotic areas.

- Stop the intake of hydroxychloroquine is the treatment of choice, though it may only ameliorate the skin lesions but never completely solve them.

Contributors RMMDGI was one of the doctors who assisted the patient during this case, gather the information, obtained the images and wrote the text. RR and CAL were also part of the team who observed the patient and revised the text written by the corresponding author.

Funding The authors have not declared a specific grant for this research from any funding agency in the public, commercial or not-for-profit sectors.

Competing interests None declared.

Patient consent Not required.

Provenance and peer review Not commissioned; externally peer reviewed.

\section{REFERENCES}

1 Bahloul E, Jallouli M, Garbaa S, et al. Hydroxychloroquine-induced hyperpigmentation in systemic diseases: prevalence, clinical features and risk factors: a cross-sectional study of 41 cases. Lupus 2017;26:1304-8.

2 Coulombe J, Boccara 0. Hydroxychloroquine-related skin discoloration. CMAJ 2017;189:E212.

3 Sawalha AH. Hydroxychloroquine-induced hyperpigmentation of the skin. J Rheumatol 2015;42:135-6. 
Copyright 2018 BMJ Publishing Group. All rights reserved. For permission to reuse any of this content visit https://www.bmj.com/company/products-services/rights-and-licensing/permissions/

BMJ Case Report Fellows may re-use this article for personal use and teaching without any further permission.

Become a Fellow of BMJ Case Reports today and you can:

- Submit as many cases as you like

- Enjoy fast sympathetic peer review and rapid publication of accepted articles

Access all the published articles

- Re-use any of the published material for personal use and teaching without further permission

For information on Institutional Fellowships contact consortiasales@bmjgroup.com

Visit casereports.bmj.com for more articles like this and to become a Fellow 